\title{
Avaliação de uma metodologia prática para o mapeamento de plantas daninhas
}

Luiz A. Balastreire ${ }^{1}$ \& Fábio H.R. Baio ${ }^{2}$

\author{
1 ESALQ/USP. Piracicaba, SP. Fone: (19) 3429-4165. E-mail: labalast@esalq.usp.br (Foto) \\ 2 ESALQ/USP. Fone: (14) 452-1811.E-mail: jacto@jacto.com.br
}

Protocolo $106-30 / 02 / 2000$

\begin{abstract}
Resumo: Está sendo desenvolvida uma nova tecnologia, chamada Agricultura de Precisão e, com ela, vêm surgindo novos equipamentos, capazes de realizar a aplicação localizada de defensivos. Muitos desses equipamentos necessitam de um mapeamento prévio do alvo de interesse para sua utilização. O propósito deste trabalho foi a avaliação de uma metodologia prática para o mapeamento de plantas daninhas pelo contorno das reboleiras com um quadriciclo. Foram realizados dois mapeamentos em um mesmo campo agrícola, com quinze dias de intervalo. A metodologia aplicada para o mapeamento de plantas daninhas mostrou-se eficiente nas condições avaliadas. Foi possível a obtenção dos mapas de plantas daninhas com três níveis de infestação. Verificou-se a necessidade de um planejamento para a realização do mapeamento, levando-se em consideração a posterior aplicação localizada de defensivos.
\end{abstract}

Palavras-chave: aplicação localizada de defensivos, agricultura de precisão, mapeamento de plantas daninhas

\section{Evaluation of a practical methodology for weed mapping}

\begin{abstract}
Several items of equipment able to realize site specific chemical application have been developed. Equipment for site specific chemical application needs a prescription map of the target area. The purpose of this work was to evaluate a practical method for weed mapping by driving over the patch contour with an All Terrain Vehicle (ATV). Two weed maps were created for the same agricultural field. The proposed method for weed mapping was considered efficient for the evaluated conditions. The weed maps obtained showed three infestations levels. An important conclusion obtained was that timing to perform the weed mapping is a very important factor to be considered for site specific chemical application.
\end{abstract}

Key words: patch spraying, precision farming, weed mapping

\section{INTRODUÇÃO}

Observações em campo indicam tendência das plantas daninhas em formarem padrões espaciais de agregação (Nordmeyer et al., 1997). Esta distribuição, embora irregular, implica no fato de certas regiões do campo estarem livres de plantas daninhas ou abaixo do nível de dano econômico. A possibilidade da detecção e mapeamento das reboleiras de plantas daninhas cria a oportunidade do controle somente nas suas áreas de ocorrência.

A habilidade de se descrever e mapear a distribuição espacial das plantas daninhas é o primeiro passo para o estudo da variabilidade espacial das mesmas e da determinação da melhor metodologia para a aplicação localizada de defensivos, de acordo com a agricultura de precisão.

As reboleiras de plantas daninhas podem ser permanentes durante vários anos e em um mesmo local, devido a determinadas características biológicas de algumas espécies, como sistema radicular perene; por outro lado, a distribuição das plantas daninhas é influenciada por fatores locais, como: topografia, umidade do solo, drenagem, compactação e fertilidade do solo, sendo este último um dos fatores de maior importância (Häusler \& Nordmeyer, 1995). Estes fatores interferem na densidade e na composição das populações de plantas daninhas.

A metodologia para o mapeamento de plantas daninhas para posterior aplicação localizada de defensivos, deve proporcionar um mapeamento rápido, devido ao dinamismo das suas populações; além disso, ela deve ser simples, facilitando a execução do mapeamento, havendo um período ideal para a sua execução, levando-se em consideração o momento da realização do controle das plantas daninhas; por outro lado, devido ao fator de escala econômica, deve ser uma metodologia que possa ser aplicada em áreas extensas. 
Alguns fatores devem ser observados no momento do mapeamento, como densidade das plantas daninhas, espécies presentes e estágio de desenvolvimento (Baio \& Balastreire, 1999).

Os dados requeridos para a geração dos mapas de plantas daninhas e posterior criação dos mapas de prescrição, podem ser derivados do caminhamento pelo contorno das reboleiras, fotografia aérea, dados de anos anteriores, sensoriamento remoto, amostragem sistemática, registro das plantas daninhas durante a colheita ou durante os tratos culturais, propriedades do solo e da experiência do agricultor (Nordmeyer et al., 1997).

O mapeamento de plantas daninhas requer, na maioria dos casos, um sistema de posicionamento, para o que pode ser utilizado um DGPS (Differential Global Positioning System) com correção diferencial em tempo real ou pós-processada (Webster \& Cardina, 1997).

Colliver et al. (1996) avaliaram os métodos de mapeamento de plantas daninhas por amostragens sistemáticas, pelo contorno das reboleiras e pelo método linear, em uma mesma área e obtiveram, como resultados, infestações de plantas daninhas de $68,6,66,5$ e 90\% da área total para os primeiro, segundo e terceiro métodos, respectivamente, e chegaram à conclusão de que o método mais eficiente é aquele onde se contornam as reboleiras, por ser mais preciso que o método linear e mais rápido que o método por amostragem.

Walter et al. (1997) relatam que o método linear de mapeamento é mais proveitoso onde há somente uma espécie de planta daninha. Jensen \& Hall (1999) citam que o mapeamento de plantas daninhas pode ser realizado mais rapidamente com o auxílio de um quadriciclo ATV (All Terrain Vehicle) equipado com DGPS, computador e programa para o mapeamento.

Enfim, o presente trabalho teve como objetivo a avaliação de uma metodologia prática para o mapeamento de plantas daninhas pelo contorno das reboleiras, visando à aplicação localizada de defensivos em um campo agrícola brasileiro.

\section{MATERIAL E MÉTODOS}

O ensaio foi realizado em um campo experimental na propriedade Morada do Sol, no município de Araguari, MG, cujo campo experimental possui uma área de $72 \mathrm{ha}$, em terreno plano, cultivado no sistema de plantio direto e com solo coberto por restos culturais de soja, em pousio.

O sistema DGPS utilizado para o mapeamento de plantas daninhas foi um receptor GPS Trimble, específico para a agricultura de precisão, modelo AG 132 de 12 canais, que utiliza o código C/A para os cálculos de posicionamento. Este equipamento recebe correção diferencial via satélite para o DGPS, sendo este serviço disponibilizado pela Empresa Racal.

Um quadriciclo ATV Polaris foi utilizado durante o mapeamento e a este equipamento foram montados o DGPS e um notebook, que possuía um programa de agricultura de precisão específico para mapeamentos e aplicação localizada.

O programa utilizado no mapeamento de plantas daninhas foi o FieldLink ${ }^{\circledR}$ da Agris, que possui uma interface com o GPS para o georreferenciamento e, para a geração e análise dos mapas de plantas daninhas, utilizou-se o programa AgLink ${ }^{\circledR}$, da Empresa Agris.

A metodologia para o mapeamento de plantas daninhas adotada foi aquela onde são percorridas as reboleiras por elas formadas, através da qual foram percorridos os perímetros das reboleiras de plantas daninhas com o quadriciclo, mapeando-as com o DGPS.

Como no Brasil o padrão da distribuição espacial das plantas daninhas é muito homogêneo, houve a necessidade de uma avaliação preliminar na área (Baio \& Balastreire, 1999).

Em situações onde foi possível identificar-se as reboleiras com nitidez, o mapeamento foi realizado contornando-se as manchas de plantas daninhas com maior densidade e, onde foi difícil identificar-se as reboleiras de plantas daninhas devido à homogeneidade da distribuição espacial, o mapeamento foi realizado contornando-se as manchas de menor densidade.

Para a verificação da densidade das plantas daninhas presentes, Nordmeyer et al. (1997) sugerem a contagem em uma área amostral de $0,25 \mathrm{~m}^{2}$. Também foram observados dados referentes às espécies de plantas daninhas presentes e ao estágio de desenvolvimento de cada espécie.

Devido à extensão da área experimental, criou-se uma grade de 2 ha sobre a área mapeada, visualizada na tela do computador do quadriciclo, facilitando a identificação dos locais já mapeados e adotados três níveis de infestação: zero ou muito baixa, média e alta infestação; esses níveis foram escolhidos de acordo com as densidades das espécies presentes na área (Rew et al., 1996).

Realizaram-se dois mapeamentos de plantas daninhas na mesma área, com 15 dias de intervalo, em que o primeiro mapeamento foi realizado em condições onde não seria possível a aplicação de herbicida, devido à baixa umidade do solo e ao estresse hídrico das plantas daninhas, e o segundo 15 dias após o primeiro, em condições em que a umidade do solo já havia sido restabelecida, devido ao início das chuvas no local. Foi realizada, então, uma análise comparativa entre os mapas de plantas daninhas obtidos.

\section{RESULTADOS E DISCUSSÃO}

A metodologia proposta para o mapeamento de plantas daninhas foi considerada eficaz para as condições avaliadas e os mapas dessas plantas permitiram a representação da distribuição espacial das populações das plantas daninhas no campo; desta forma, é possível a utilização desses mapas para a criação dos mapas de prescrição e sua posterior utilização para a aplicação localizada de defensivos.

As espécies de plantas daninhas identificadas na área experimental e seus estágios de desenvolvimento no primeiro mapeamento, foram:

- trapoeraba (Commelina benghalensis L.) planta adulta

- guanxuma (Sida santaremnensis Monteiro) planta adulta

- picão preto (Bidens pilosa L.) planta adulta em fase reprodutiva

- buva (Conyza bonariensis (L.) Cronq.) planta adulta em fase reprodutiva

- falsa-serralha (Emilia sonchifolia DC.) planta adulta.

No primeiro mapeamento, a área mapeada foi de 72 ha, com predominância de trapoeraba e guanxuma, enquanto as outras espécies ocorreram esporadicamente. Foi possível a identificação visual das reboleiras dessas espécies; o mapeamento desta área foi concluído em $45 \mathrm{~min}$. 
Observaram-se três condições no campo experimental:

- baixa infestação ou nula, situação em que não havia a presença de plantas daninhas ou esta infestação estava abaixo do nível de dano econômico, ou seja, havia a presença de até uma planta $\mathrm{m}^{-2}$ de guanxuma ou trapoeraba (Figura 1A);

- média infestação, indício da presença de algumas plantas daninhas das espécies mapeadas. Para a guanxuma, foi considerada média infestação até 5 plantas $\mathrm{m}^{-2} \mathrm{e}$, para a trapoeraba, média infestação aquela com até 2 plantas $\mathrm{m}^{-2}$ (Figura 1B);

- alta infestação, situação onde havia a presença de mais de 5 plantas $\mathrm{m}^{-2}$ de guanxuma e mais de 2 plantas $\mathrm{m}^{-2}$ de trapoeraba (Figura 1C).

\section{A. Baixa infestação}

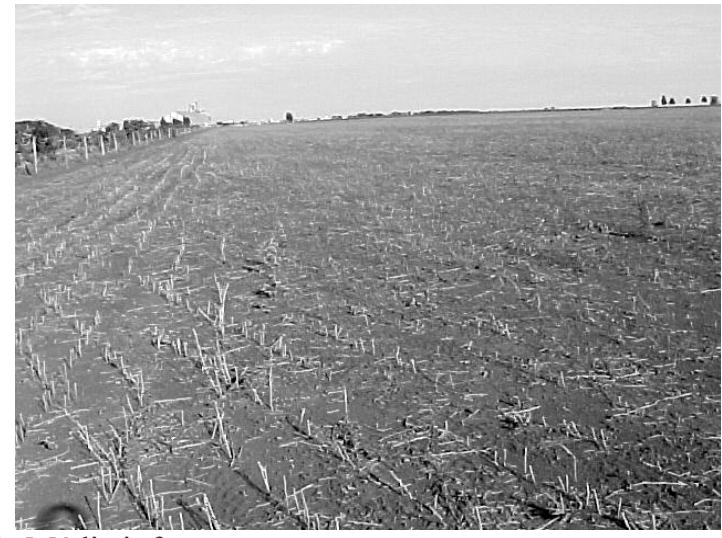

B. Média infestação

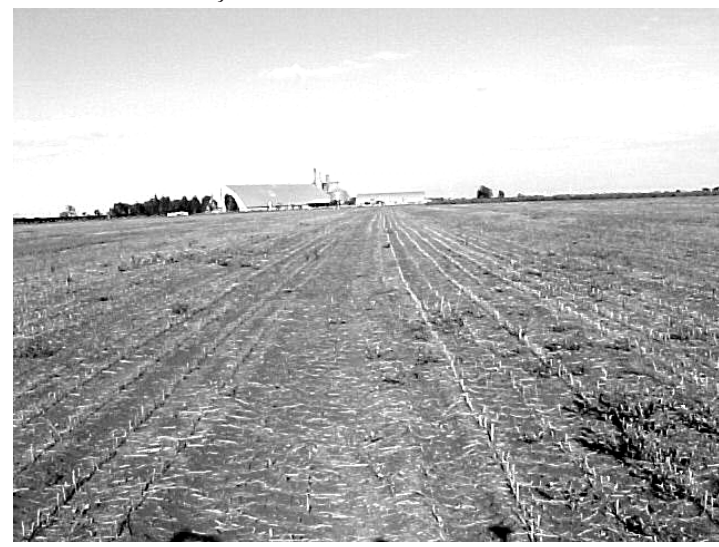

C. Alta infestação


Figura 1. Condições encontradas no campo experimental durante o primeiro mapeamento: baixa (A); média (B); e alta (C) infestação de plantas daninhas
A representação do mapa de plantas daninhas obtida no primeiro mapeamento pode ser observada na Figura $2 \mathrm{~A}$. Na área total, de 72 ha, $13,47 \%$ ou 9,7 ha foram compostas por reboleiras de alta infestação de plantas daninhas, $82,88 \%$ da área total ou 59,67 ha se compunham de reboleiras de média infestação, e 1,67\% da área total, ou 2,63 ha, por reboleiras de baixa ou nula infestação.

\section{A. Primeiro mapeamento}
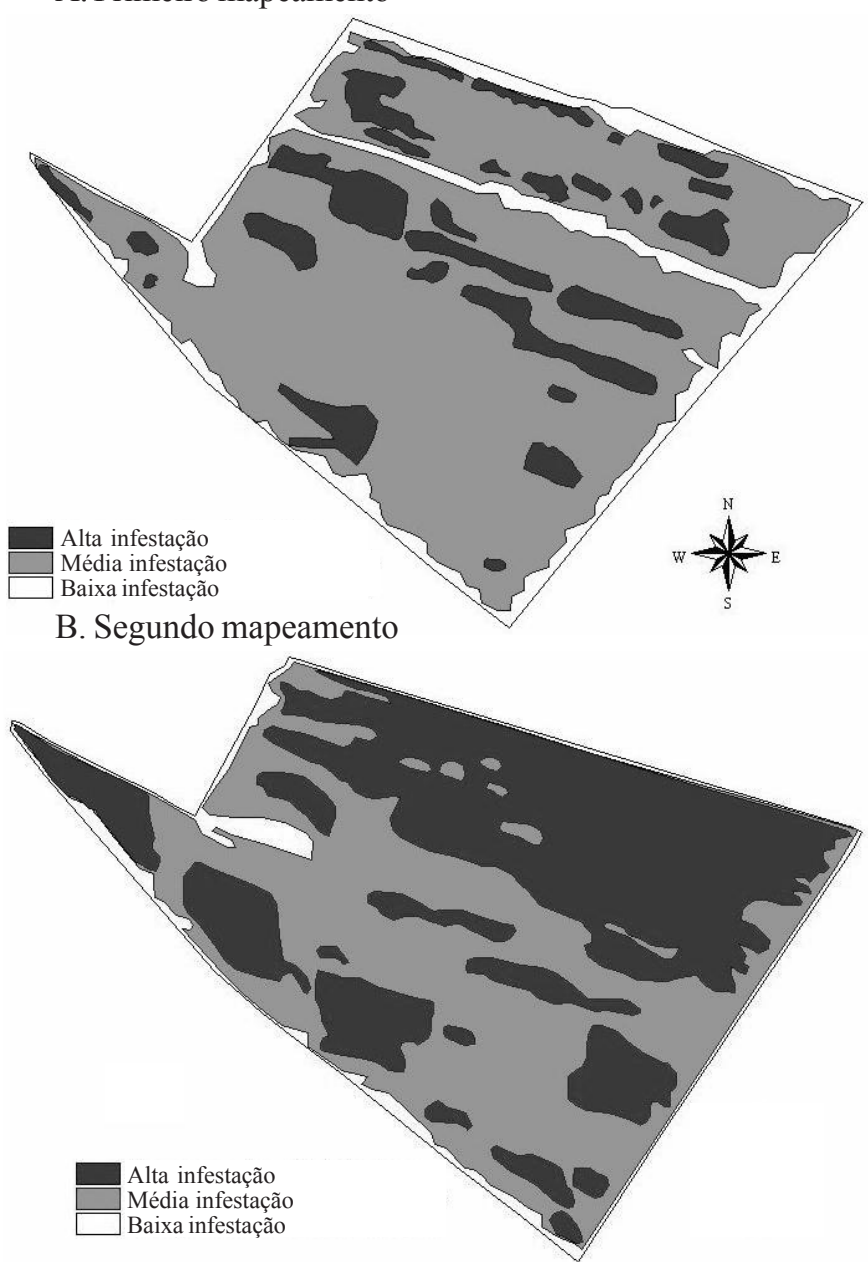

Figura 2. Ilustração dos mapas de plantas daninhas, obtidas no primeiro (A) e no segundo (B) mapeamentos da área experimental

A aplicação do herbicida em dosagem única em área total requer a adoção de uma dosagem para o controle das plantas daninhas naquelas áreas de maior infestação, enquanto com a aplicação localizada de defensivos se pode variá-las de acordo com a necessidade específica para cada local. Desta forma, verifica-se o potencial econômico da aplicação localizada de defensivos na agricultura de precisão, devido à redução na utilização de herbicidas.

As espécies de plantas daninhas identificadas na área experimental no segundo mapeamento, foram:

- trapoeraba (Commelina benghalensis L.) planta adulta

- guanxuma (Sida santaremnensis Monteiro) planta adulta

- picão preto (Bidens pilosa L.) planta adulta em fase reprodutiva

- buva (Conyza bonariensis (L.) Cronq.) planta adulta em fase reprodutiva

- falsa-serralha (Emilia sonchifolia DC.) planta adulta 
- capim marmelada (Brachiaria plantaginea (Link) Hitchc.) estágio inicial de desenvolvimento, com duas a três folhas

- capim pé-de-galinha (Eleusine indica (L.) Gaertn) estágio inicial de desenvolvimento

- capim colonião (Panicum maximum Jacq.) estágio inicial de desenvolvimento

- capim favorito (Rhynchelytrum repens (Willd.) C.E. Hubb.) estágio inicial de desenvolvimento.

O segundo mapeamento foi realizado no mesmo campo experimental, em que duas regiões distintas foram observadas, uma com predominância de guanxuma e trapoeraba, e outra com predominância do capim marmelada.

Verificou-se a necessidade da diminuição da área mapeada, para 52,49 ha no segundo mapeamento de plantas daninhas, devido ao início do plantio de milho em uma região do terreno na época em que foi realizado o segundo mapeamento, o qual foi concluído em 1 h e $30 \mathrm{~min}$; o aumento do tempo, em $45 \mathrm{~min}$, para a sua realização, se deveu à emergência do capim marmelada, que dificultou o processo de identificação visual das reboleiras.

A representação do mapa de plantas daninhas obtida no segundo mapeamento, pode ser observada na Figura 2B. A área total possui 52,49 ha, $48,02 \%$ ou 25,21 ha foi composta por reboleiras de alta infestação de plantas daninhas, enquanto $46,86 \%$ de sua área ou 24,65 ha, foram compostas por reboleiras de média infestação, enquanto $5,01 \%$ da área total, ou 2,63 ha, se compunham por reboleiras de baixa ou nula infestação.

Comparando-se os mapas das Figuras 2A e 2B, observa-se que houve coerência na distribuição espacial das plantas daninhas nos dois mapeamentos, além de um aumento de $11,74 \%$ da área considerada de alta infestação de plantas daninhas, devido às chuvas no intervalo entre os dois mapeamentos, promovendo a emergência de outras espécies, principalmente do capim marmelada; assim, verificou-se a possibilidade de fracasso no controle localizado de plantas daninhas, se o mapeamento e o controle não forem planejados nem realizados em um momento ideal.

\section{CONCLUSÕES}

1. A metodologia utilizada e avaliada para o mapeamento de plantas daninhas pelo contorno das reboleiras, mostrou-se adequada às condições analisadas. Pôde-se obter os mapas de plantas daninhas passíveis de serem utilizados para a aplicação localizada de defensivos, observando-se três condições de infestação de plantas daninhas no campo experimental: baixa ou nula, média, e alta infestação.
2. O tempo necessário para a conclusão do mapeamento está diretamente relacionado à complexidade da distribuição espacial das plantas daninhas.

3. Há necessidade do planejamento do momento ideal para a realização do mapeamento, levando-se em consideração a posterior aplicação localizada de defensivos.

\section{AGRADECIMENTOS}

Às Empresas Máquinas Agrícolas Jacto S.A., pelo apoio técnico, e AGRISAT, por haver cedido sua área para o experimento.

\section{LITERATURA CITADA}

Baio, F.H.R.; Balastreire, L.A. Aplicação localizada de defensivos, um importante conceito da agricultura de precisão. Piracicaba: ESALQ/USP, 1999. 76p. Relatório Técnico do Estágio Profissionalizante em Engenharia Agronômica

Colliver, C.T.; Maxwell, B.D.; Tyler, D.A.; Roberts, D.W.; Long, D.S. Georeferencing wild oat infestations in small grains: Accuracy and efficiency of three weed survey techniques. ln: Precision agriculture, 1, 1996, Madison. Resumos... Madison: ASA-CSSA-SSSA, 1996. p.453-463.

Häusler, A.; Nordmeyer, H. Impact of soil on weed distribution. In: Seminar on site specific farming, 1995, Denmark. Resumos... Denmark: Institute for Weed Research, 1995. p.186-189.

Jensen, T.; Hall, L. Precision farming: Working toward an ideal. GPS World, Danvers, v.11, n.4, p.38-42, 1999.

Nordmeyer, H.; Häusler, A.; Niemann, P. Patchy weed control as an approach in precision farming. In: Precision agriculture, 2, 1997, Warwick. Resumos... Warwick: SCI, 1997. v.1, p.307-314.

Rew, L.J.; Cussans, G.W.; Mugglestone, M.A.; Miller, P.C.H. A technique for mapping the spatial distribution of Elymus repens, with estimates of the potential reduction in herbicide usage from patch spraying. Weed Research, Edinburgh, v.36, n.4, p.283-292, 1996.

Walter, A.M.; Heisel, T.; Chistensen. S. Shortcuts in weed mapping. In: Precision agriculture, 2, 1997, Warwick. Resumos... Warwick: SCI, 1997. v.2, p.777-784.

Webster, T.M.; Cardina, J. Accuracy of a global positioning system for weed mapping. Weed Technology, Champaign, v.11, n.3, p.782-786, 1997. 